\title{
CIMT does not identify early vascular changes in childhood acute lymphoblastic leukemia survivors
}

\author{
Tomasz Ociepa ${ }^{1, A-F}$, Wioletta Posio ${ }^{2, B}$, Marcin Sawicki ${ }^{2, B}$, Tomasz Urasińskil, ${ }^{1, A D-F}$ \\ ${ }^{1}$ Department of Pediatrics, Hemato-Oncology and Gastroenterology, Pomeranian Medical University, Szczecin, Poland \\ ${ }^{2}$ Department of Diagnostic Imaging and Interventional Radiology, Pomeranian Medical University, Szczecin, Poland \\ A - research concept and design; B - collection and/or assembly of data; C - data analysis and interpretation; \\ $D$ - writing the article; $E$ - critical revision of the article; $F$ - final approval of the article
}

\section{Address for correspondence \\ Tomasz Ociepa}

E-mail: tociepa@gmail.com

\section{Funding sources}

None declared

\section{Conflict of interest}

None declared

\section{Acknowledgements}

The authors thank Dr. Maciej Donotek

for technical support

Received on June 2, 2019

Reviewed on July 11, 2019

Accepted on December 5, 2019

Published online on February 19, 2020

Cite as

Ociepa T, Posio W, Sawicki M, Urasiński T. CIMT does not identify early vascular changes in childhood acute lymphoblastic leukemia survivors. Adv Clin Exp Med. 2020:29(2):243-249. doi:10.17219/acem/115082

DOI

10.17219/acem/115082

\section{Copyright}

Copyright by Author(s)

This is an article distributed under the terms of the

Creative Commons Attribution 3.0 Unported (CC BY 3.0)

(https://creativecommons.org/licenses/by/3.0/)

\begin{abstract}
Background. Childhood acute lymphoblastic leukemia (ALL) survivors are at an increased risk of cardiovascular disease development. It is believed that in the general population, this risk can be predicted with carotid intima-media thickness (CIMT) measurement.
\end{abstract}

Objectives. The objective of this study was to assess CIMT and to investigate the effects of blood pressure (BP) and lipid profile values on CIMT in childhood ALL survivors.

Material and methods. The study group comprised 81 childhood ALL survivors aged 5 - 25 years. The control group consisted of 52 age- and sex-comparable healthy children. Carotid intima-media thickness measurement, 24-hour BP monitoring and lipid profiles were evaluated in patients and controls.

Results. Despite significantly higher proportion of subjects with arterial hypertension (AH) (30/81 vs 10/52; $p=0.0315)$, the mean values of CIMT were not statistically different in childhood ALL survivors as compared to controls ( $0.4303 \pm 0.03$ vs $0.4291 \pm 0.03 ; p=0.81$ and $1.096 \pm 0.74$ vs $1.027 \pm 0.55 ; p=0.56$, respectively). Carotid intima-media thickness values were not statistically higher in ALL survivors with AH as compared to ALL survivors with normal BP ( $0.433 \pm 0.03$ vs $0.428 \pm 0.03 ; p=0.82$ ). A significant positive correlation between 24-hour systolic BP standard deviation score (SDS) and CIMT-SDS in childhood ALL survivors was found ( $r=0.29, p=0.009)$, whereas such correlation was not observed in healthy controls $(r=0.12$, $p=0.39$ ). A significant correlation between $z-$ score body mass index (BMI) and CIMT was found in controls $(r=0.29, p=0.031)$ but not in childhood ALL survivors $(r=-0.05, p=0.64)$. No significant correlations between CIMT and other measured variables were found. Carotid intima-media thickness did not significantly correlate with time since ALL diagnosis $(r=0.09, p=0.39)$.

Conclusions. Carotid intima-media thickness measurement shows limited feasibility and diagnostic accuracy for early assessment of vascular alteration in childhood ALL survivors. Other tests are needed to predict cardiovascular risk in childhood ALL survivors at the early stage of the follow-up.

Key words: children, cardiovascular risk, arterial hypertension, acute lymphoblastic leukemia, carotid intimamedia thickness 


\section{Introduction}

Carotid intima-media thickness (CIMT) is a recognized marker of endothelial dysfunction. Carotid intima-media thickness measurement has become a useful non-invasive method for cardiovascular risk assessment not only for adults but also for children. ${ }^{1}$ Measurement of CIMT has established its utility as an important tool for evaluation of subclinical atherosclerosis. ${ }^{1}$ Increased CIMT was found in children with metabolic syndrome, congenital adrenal hyperplasia, obesity, type 1 diabetes mellitus, and also in childhood cancer survivors. ${ }^{2-7}$ However, the lack of pediatric, population-based reference values makes CIMT not a widely accepted marker of subclinical atherosclerosis in youth with cardiovascular risk factors. ${ }^{8}$

The developing cardiovascular system in children is highly susceptible to the toxic effects of chemotherapeutic agents and their administration may cause endothelial damage leading to endothelial dysfunction. ${ }^{9-11}$ It is believed that vascular alteration related to endothelial dysfunction leads to loss of vasodilatory capability and atherosclerosis. ${ }^{12}$

Advances in multimodal chemotherapy and supportive care have substantially improved long-term survival in children with acute lymphoblastic leukemia (ALL). ${ }^{13,14}$ However, an increased number of childhood ALL survivors is accompanied by increased prevalence of cardiovascular disease (including metabolic syndrome and coronary artery disease) in adults who survived childhood ALL. ${ }^{15,16}$ Disorders related to endothelial derangement are initiated early in life since atherosclerosis has its background in childhood. ${ }^{1,17}$ Little is known about this process in children after ALL treatment. Some published reports have confirmed endothelial dysfunction by showing lower flowmediated vasodilatation (FMD) but not increased CIMT in childhood ALL survivors as compared to controls. ${ }^{18,19}$

The aim of our study was to assess the CIMT and to investigate the effects of blood pressure (BP) and lipid profile values on CIMT in childhood ALL survivors and healthy controls.

\section{Material and methods}

\section{Patients and controls}

Between 1999 and 2012, 168 patients received intensive chemotherapy for ALL in our institution. All patients who survived in first remission and were older than 5 years were invited to participate in this study. Eighty-one patients (32 girls and 49 boys, aged 5-25 years) positively responded and were included into the study group. The control group comprised of 52 children (22 girls and 30 boys, aged 5-17 years) without any known chronic or severe medical condition. Informed consent was obtained from all parents/ legal guardians and all children. The study was approved by the Bioethics Committee of Pomeranian Medical University in Szczecin, Poland (approval No. KB-0012/69/12).

\section{Carotid intima-media thickness assessments}

Ultrasonographic studies of the common carotid arteries (CCA) were performed using ultrasound system Philips iU22 (Philips Ultrasound, Bothell, USA) with a 3-9 MHz linear array transducer. Carotid intima-media thickness was measured according to the criteria of the Mannheim Consensus. ${ }^{20}$ Depth of focus was set at $30 \mathrm{~mm}$, frame rate of $25 \mathrm{~Hz}$ and gain of $60 \mathrm{~dB}$. The arterial wall was assessed in a longitudinal B-mode view, strictly perpendicular to the ultrasound beam. Carotid intima-media thickness was measured at a distance of $10 \mathrm{~mm}$ proximal of the bifurcation and was defined as the distance from the border between the echolucent vessel lumen and the echogenic intima to the border between the echolucent media and echogenic adventitia. A semiautomatic edge detection system was used. All ultrasonographic studies were carried out twice by 2 independent radiologists. Carotid intima-media thickness values from the right and left side were recorded with the Philips iU22 software. Average CIMT values were subsequently recalculated and expressed as CIMT-standard deviation score (CIMT-SDS). This was computed according to the least mean squares (LMS) formula for SDS analysis: $\mathrm{SDS}=\left[(\mathrm{Y} / \mathrm{M}(\mathrm{t}))^{\mathrm{L}(\mathrm{t})}-1\right] /(\mathrm{L}(\mathrm{t}) \times \mathrm{S}(\mathrm{t}))$ where $\mathrm{Y}$ is the child's mean CIMT $[\mathrm{mm}], \mathrm{M}(\mathrm{t})$ is median of $\mathrm{Y}, \mathrm{L}(\mathrm{t})$ is the measure of skewness, and $\mathrm{S}(\mathrm{t})$ is the coefficient of variation. The LMS formula and reference values for the CIMT measurements were extracted from the data published by Doyon et al. ${ }^{21}$

\section{Definition and diagnosis of arterial hypertension}

Blood pressure assessments were performed with the use of a standard oscillometric 24-hour ambulatory blood pressure monitoring (ABPM) device (HolCARD CR-07; Aspel S.A., Zabierzów, Poland). Measurements were taken every 20 min during daytime (08:00-22:00) and every $30 \mathrm{~min}$ during nighttime (22:00-08:00). Blood pressure values were recorded all day (daytime and nighttime, respectively) as systolic (SBP), diastolic (DBP) and mean arterial blood pressure (MAP). Only readings of SBP $<240 \mathrm{~mm} \mathrm{Hg}$ and $>70 \mathrm{~mm} \mathrm{Hg}$, and $\mathrm{DBP}<140 \mathrm{~mm} \mathrm{Hg}$ and $>40 \mathrm{~mm} \mathrm{Hg}$ were considered valid. Arterial hypertension $(\mathrm{AH})$ was defined as either mean SBP and/or mean DBP $\geq 95^{\text {th }}$ percentile for age, height and sex during any recorded (daytime and/or nighttime) period.

All mean ABPM values (SBP, DBP and MAP) were recalculated using the LMS formula and expressed as 24-hour SBP-SDS, DBP-SDS and MAP-SDS. The LMS formula and reference values for the ABPM measurements were extracted from the data published by Wühl et al. ${ }^{22}$

\section{Clinical and biochemical evaluation}

All patients and subjects from the control group underwent a complete physical examination with assessment 
Table 1. Characteristics of study patients and controls

\begin{tabular}{|c|c|c|c|}
\hline Parameters & $\operatorname{ALL}(\mathrm{n}=81)$ & Controls $(n=52)$ & p-value \\
\hline Mean age [years], median & $12.1 \pm 4.6(12)$ & $11.7 \pm 4.2(12)$ & 0.63 \\
\hline Sex, female/male & $32 / 49$ & $22 / 30$ & 0.59 \\
\hline Mean age at ALL diagnosis [years], median & $6.6 \pm 4.27(6)$ & NA & - \\
\hline Mean follow-up time [years], median & $5.7 \pm 3.96(5)$ & NA & - \\
\hline Follow-up time $\leq 5$ years, number of patients (\%) & $36(44.44)$ & NA & - \\
\hline Follow-up time $>5$ years, number of patients (\%) & $45(55.56)$ & NA & - \\
\hline $\mathrm{AH}$, number of patients (\%) & $30(37)$ & $10(19.2)$ & 0.0315 \\
\hline 24-hour SBP, mean & $114.6 \pm 9.2$ & $113.7 \pm 7.6$ & 0.53 \\
\hline 24-hour DBP, mean & $65.8 \pm 7.5$ & $64.0 \pm 5.7$ & 0.14 \\
\hline 24-hour MAP, mean & $89.5 \pm 7.5$ & $88.2 \pm 5.7$ & 0.28 \\
\hline 24-hour SBP-SDS & $0.336 \pm 1.26$ & $0.284 \pm 1.05$ & 0.81 \\
\hline 24-hour DBP-SDS & $-0.26 \pm 1.28$ & $-0.569 \pm 1.09$ & 0.15 \\
\hline 24-hour MAP-SDS & $1.415 \pm 1.31$ & $1.205 \pm 0.96$ & 0.32 \\
\hline BMI $\left[\mathrm{kg} / \mathrm{m}^{2}\right]$ & $19.6 \pm 3.99$ & $18.9 \pm 4.39$ & 0.41 \\
\hline BMI, z-score & $0.44 \pm 1.03$ & $-0.10 \pm 1.40$ & 0.01 \\
\hline BMI-for-age ( $\geq 90$ percentile), number of patients (\%) & $20(24.7)$ & $7(13.5)$ & 0.13 \\
\hline BMI-for-age ( $\geq 95$ percentile), number of patients (\%) & $10(12.3)$ & $3(5.8)$ & 0.34 \\
\hline Total cholesterol [mg/dL] & $162.9 \pm 34.6$ & $144.7 \pm 33.2$ & 0.003 \\
\hline Triglycerides [mg/dL] & $96.8 \pm 71.2$ & $80.7 \pm 46.9$ & 0.15 \\
\hline $\mathrm{LDL}[\mathrm{mg} / \mathrm{dL}]$ & $92.0 \pm 28.6$ & $85.1 \pm 26.9$ & 0.17 \\
\hline $\mathrm{HDL}[\mathrm{mg} / \mathrm{dL}]$ & $60.5 \pm 14.9$ & $51.4 \pm 16.1$ & 0.001 \\
\hline
\end{tabular}

ALL - childhood acute lymphoblastic leukemia survivors; AH - arterial hypertension; BMI - body mass index; SBP - systolic blood pressure; DBP - diastolic blood pressure; MAP - mean arterial pressure; SDS - standard deviation score; NA - not applicable; LDL - low-density lipoprotein; HDL - high-density lipoprotein.

of weight and height. Body mass index (BMI) as well as z-score BMI were subsequently calculated. Fasting blood samples were collected from all study subjects for serum total cholesterol, triglycerides, low-density lipoprotein (LDL), and high-density lipoprotein (HDL) measurements.

\section{Statistical analysis}

The data was expressed as mean \pm standard deviation (SD). Continuous variables between groups (age, age at diagnosis, time of follow up, z-score BMI values, and SDS values) were compared using the two-tailed Mann-Whitney test. Fisher's exact test was used to compare unpaired, nominal variables. Pearson's coefficients or Spearman's coefficients were used to estimate correlations between longitudinal data. P-values $\leq 0.05$ were considered significant.

The statistical analysis was performed using STATISTICA v. 13 (StatSoft, Inc., Tulsa, USA) software.

\section{Results}

Patient and control characteristics are presented in Table 1.

Mean age at evaluation of CIMT was 12.1 years and 11.7 years in the ALL and control cohort, respectively.
The number of patients with AH was significantly higher in the ALL cohort (30/81) as compared to controls (10/52) $(\mathrm{p}=0.0315$; odds ratio $(\mathrm{OR})=2.47 ; 95 \%$ confidence interval $(95 \% \mathrm{CI})=1.08-5.63)$. Body mass index was not statistically different in the study groups; however, z-score BMI was statistically higher in the ALL cohort. Numbers of patients with BMI-for-age above or equal to $90^{\text {th }}$ and $95^{\text {th }}$ percentile were not different in both cohorts.

It was found that right CIMT, left CIMT and average CIMT as well as CIMT-SDS were not statistically different between childhood ALL survivors and the control group. This data is presented in Table 2.

Right CIMT, left CIMT and average CIMT as well as CIMT-SDS were found not to be statistically higher in childhood ALL survivors and controls with AH

Table 2. Comparison of CIMT in childhood ALL survivors and controls

\begin{tabular}{|l|c|c|c|}
\multicolumn{1}{|c|}{ Variables } & ALL $(n=81)$ & $\begin{array}{c}\text { Controls } \\
(n=52)\end{array}$ & p-value \\
\hline CIMT R $[\mathrm{mm}]$ & $0.4305 \pm 0.03$ & $0.4297 \pm 0.03$ & 0.89 \\
\hline CIMT L $[\mathrm{mm}]$ & $0.4300 \pm 0.03$ & $0.4285 \pm 0.03$ & 0.78 \\
\hline CIMT average $[\mathrm{mm}]$ & $0.4303 \pm 0.03$ & $0.4291 \pm 0.03$ & 0.81 \\
\hline CIMT-SDS & $1.096 \pm 0.74$ & $1.027 \pm 0.55$ & 0.56 \\
\hline
\end{tabular}

ALL - childhood acute lymphoblastic leukemia survivors; CIMT - carotid intima-media thickness; L - left; R - right; SDS - standard deviation score. 
Table 3. Comparison of CIMT in childhood ALL survivors and controls with AH and with normal blood pressure

\begin{tabular}{|l|c|c|c|c|c|c|c|c|}
\multicolumn{1}{|c|}{ Variables } & ALL AH(+) $(n=30)$ & ALL AH(-) $(n=51)$ & $p$-value & Controls AH(+) $(n=10)$ & Controls AH $(-)(n=42)$ & $p$-value & * p-value \\
\hline CIMT R [mm] & $0.435 \pm 0.04$ & $0.428 \pm 0.04$ & 0.78 & $0.431 \pm 0.04$ & $0.429 \pm 0.04$ & 0.89 & 0.89 \\
\hline CIMT L $[\mathrm{mm}]$ & $0.431 \pm 0.03$ & $0.429 \pm 0.03$ & 0.89 & $0.426 \pm 0.04$ & $0.429 \pm 0.03$ & 0.78 & 0.78 \\
\hline CIMT average $[\mathrm{mm}]$ & $0.433 \pm 0.03$ & $0.428 \pm 0.03$ & 0.82 & $0.428 \pm 0.03$ & $0.429 \pm 0.02$ & 0.93 & 0.93 \\
\hline CIMT-SDS & $1.291 \pm 0.91$ & $0.981 \pm 0.61$ & 0.07 & $1.034 \pm 0.49$ & $1.024 \pm 0.57$ & 0.95 & 0.95 \\
\hline
\end{tabular}

ALL - childhood ALL survivors; AH (+) - arterial hypertension; AH (-) - normal blood pressure; CIMT - carotid intima-media thickness; L - left; R - right; SDS - standard deviation score; ${ }^{*}$ - -values for comparison of CIMT in childhood ALL survivors with AH and normal blood pressure controls.

Table 4. Comparison of CIMT, blood pressure values as well as lipid profile in childhood ALL survivors in relation to the follow-up time

\begin{tabular}{|l|c|c|c|}
\multicolumn{1}{|c|}{ Variables } & $\begin{array}{c}\text { Follow-up } \leq 5 \\
\text { years }(\mathbf{n}=45)\end{array}$ & $\begin{array}{c}\text { Follow-up }>5 \\
\text { years }(\mathbf{n}=36)\end{array}$ & p-value \\
\hline CIMT R [mm] & $0.4276 \pm 0.03$ & $0.4342 \pm 0.04$ & 0.39 \\
\hline CIMT L [mm] & $0.4248 \pm 0.03$ & $0.4365 \pm 0.04$ & 0.10 \\
\hline CIMT average [mm] & $0.4262 \pm 0.03$ & $0.4353 \pm 0.03$ & 0.18 \\
\hline CIMT-SDS & $1.167 \pm 0.78$ & $1.00 \pm 0.67$ & 0.34 \\
\hline 24-hour SBP, mean & $113.4 \pm 9.9$ & $116.2 \pm 8.0$ & 0.17 \\
\hline 24-hour DBP, mean & $65.9 \pm 8.8$ & $65.7 \pm 5.5$ & 0.91 \\
\hline 24-hour MAP, mean & $88.7 \pm 8.5$ & $90.6 \pm 5.9$ & 0.26 \\
\hline 24-hour SBP, SDS & $0.545 \pm 1.29$ & $0.073 \pm 1.18$ & 0.09 \\
\hline 24-hour DBP, SDS & $-0.193 \pm 1.43$ & $-0.345 \pm 1.07$ & 0.60 \\
\hline 24-hour MAP, SDS & $1.451 \pm 1.41$ & $1.369 \pm 1.19$ & 0.78 \\
\hline Total cholesterol [mg/dL] & $161.9 \pm 34.6$ & $164.2 \pm 33.2$ & 0.76 \\
\hline Triglycerides [mg/dL] & $102.5 \pm 71.2$ & $89.6 \pm 46.9$ & 0.42 \\
\hline LDL [mg/dL] & $91.0 \pm 28.6$ & $93.3 \pm 26.9$ & 0.72 \\
\hline HDL [mg/dL] & $58.3 \pm 14.9$ & $63.2 \pm 16.1$ & 0.14 \\
\hline
\end{tabular}

CIMT - carotid intima-media thickness; L - left; $R$ - right; SBP - systolic blood pressure; DBP - diastolic blood pressure; MAP - mean arterial pressure; SDS - standard deviation score.

as compared to cohorts with normal BP. Carotid intimamedia thickness values were found not to be statistically higher in childhood ALL survivors with AH when compared only to normal BP controls. This data is presented in Table 3.

Numbers of subjects with high ( $\geq 1$ SDS) and low ( $<1$ SDS) CIMT were not different in childhood ALL survivors group compared to control group (37/81 vs $24 / 52$ and $44 / 81$ vs 28/52; RR $=0.901,95 \% \mathrm{CI}=0.755-1.305$ and $\mathrm{RR}=1.008$, 95\% CI $=0.766-1.325, \mathrm{p}=1$, respectively).

There were no significant differences in CIMT and $\mathrm{BP}$ values as well as lipid concentrations with respect to the follow-up in childhood ALL survivors. This data is presented in Table 4.

A significant positive correlation between CIMT [mm] and $\mathrm{z}$-score BMI in the control group only was found $(\mathrm{r}=0.299, \mathrm{p}=0.031)$. A significant positive correlation between CIMT-SDS and systolic BP-SDS was found exclusively in the ALL cohort $(r=0.29, p=0.009)$. We also found a significant positive correlation between $\mathrm{z}$-score BMI and 24-hour SBP in the ALL cohort as well as in controls $(\mathrm{r}=0.23, \mathrm{p}=0.034$ and $\mathrm{r}=0.29, \mathrm{p}=0.031$, respectively). No significant correlations between CIMT [mm] or CIMTSDS and the other measured variables (including mean 24-hour BP as well as total cholesterol, triglycerides, and LDL and HDL concentrations) were found. Furthermore, no significant correlations between CIMT [mm]/CIMTSDS and the follow-up time in the ALL cohort were found $(\mathrm{r}=0.09, \mathrm{p}=0.39$ and $\mathrm{r}=0.122, \mathrm{p}=0.28)$. The correlations between CIMT and all variables measured are presented in Table 5.

The correlation between 24-hour SBP-SDS and carotid intima-media thickness SDS (CIMT-SDS) in the ALL cohort is shown in Fig. 1.

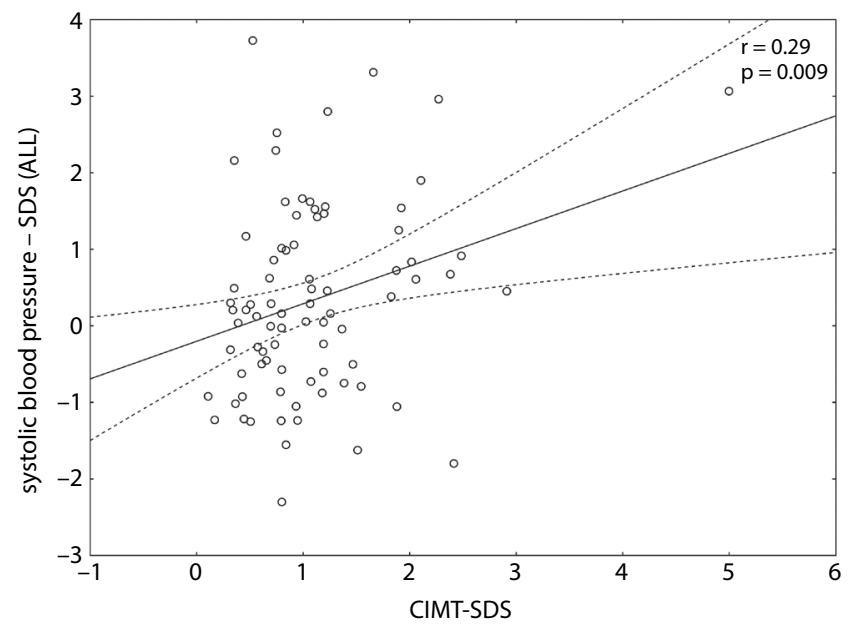

Fig. 1. The correlations between 24-hour systolic blood pressure (SBP-SDS) and carotid intima-media thickness SDS (CIMT-SDS) in childhood ALL survivors

\section{Discussion}

Assessment of cardiovascular risk in a population of childhood ALL survivors is challenging. A good, sensitive and commonly available method of early evaluation of subclinical cardiovascular disease in ALL survivors is strongly warranted and CIMT measurement as a direct estimation of arterial thickening seems to be promising. This non-invasive technique is commonly accepted as a credible instrument for cardiovascular risk assessment in adults. However, its use in the pediatric population is most commonly reserved for scientific purposes since 
Table 5. Correlations between CIMT [mm]/CIMT-SD, blood pressure values and lipid profile in childhood ALL survivors and controls

\begin{tabular}{|c|c|c|c|c|}
\hline \multirow{2}{*}{ Variables } & \multicolumn{2}{|c|}{ CIMT [mm] } & \multicolumn{2}{|c|}{ CIMT-SDS } \\
\hline & ALL & controls & ALL & controls \\
\hline $\begin{array}{l}\text { z-score BMI } \\
r \\
p \text {-value }\end{array}$ & $\begin{array}{c}-0.0532 \\
0.64\end{array}$ & $\begin{array}{l}0.2999 \\
0.031^{*}\end{array}$ & $\begin{array}{c}0.0611 \\
0.59\end{array}$ & $\begin{array}{c}0.1598 \\
0.25\end{array}$ \\
\hline $\begin{array}{l}\text { 24-hour SBP, mean } \\
r \\
p \text {-value }\end{array}$ & $\begin{array}{c}0.2096 \\
0.06\end{array}$ & $\begin{array}{c}0.1889 \\
0.18\end{array}$ & $\begin{array}{c}0.314 \\
0.19\end{array}$ & $\begin{array}{c}0.0236 \\
0.87\end{array}$ \\
\hline $\begin{array}{l}\text { 24-hour DBP, mean } \\
r \\
p \text {-value }\end{array}$ & $\begin{array}{c}0.1298 \\
0.25\end{array}$ & $\begin{array}{c}0.0444 \\
0.755\end{array}$ & $\begin{array}{c}0.066 \\
0.56\end{array}$ & $\begin{array}{c}-0.0468 \\
0.74\end{array}$ \\
\hline $\begin{array}{l}\text { 24-hour MAP, mean } \\
r \\
p \text {-value }\end{array}$ & $\begin{array}{l}0.2133 \\
0.056\end{array}$ & $\begin{array}{c}0.0348 \\
0.81\end{array}$ & $\begin{array}{c}0.1316 \\
0.24\end{array}$ & $\begin{array}{c}-0.1109 \\
0.43\end{array}$ \\
\hline $\begin{array}{l}\text { 24-hour SBP-SDS } \\
r \\
p \text {-value }\end{array}$ & $\begin{array}{c}0.1731 \\
0.12\end{array}$ & $\begin{array}{c}-0.0828 \\
0.56\end{array}$ & $\begin{array}{l}0.2904 \\
0.009^{*}\end{array}$ & $\begin{array}{c}0.1219 \\
0.39\end{array}$ \\
\hline $\begin{array}{l}\text { 24-hour DBP-SDS } \\
r \\
p \text {-value }\end{array}$ & $\begin{array}{c}0.1358 \\
0.23\end{array}$ & $\begin{array}{c}-0.0228 \\
0.87\end{array}$ & $\begin{array}{c}0.1179 \\
0.29\end{array}$ & $\begin{array}{c}-0.0376 \\
0.79\end{array}$ \\
\hline $\begin{array}{l}\text { 24-hour MAP-SDS } \\
r \\
p \text {-value }\end{array}$ & $\begin{array}{c}0.1655 \\
0.14\end{array}$ & $\begin{array}{c}-0.1411 \\
0.318\end{array}$ & $\begin{array}{c}0.1988 \\
0.07\end{array}$ & $\begin{array}{c}-0.0438 \\
0.76\end{array}$ \\
\hline $\begin{array}{l}\text { Total cholesterol }[\mathrm{mg} / \mathrm{dL}] \\
r \\
p \text {-value }\end{array}$ & $\begin{array}{c}0.0098 \\
0.93\end{array}$ & $\begin{array}{c}-0.0605 \\
0.67\end{array}$ & $\begin{array}{c}-0.0198 \\
0.86\end{array}$ & $\begin{array}{c}0.1314 \\
0.35\end{array}$ \\
\hline $\begin{array}{l}\text { Triglycerides }[\mathrm{mg} / \mathrm{dL}] \\
r \\
p \text {-value }\end{array}$ & $\begin{array}{c}0.1869 \\
0.09\end{array}$ & $\begin{array}{c}0.1455 \\
0.303\end{array}$ & $\begin{array}{c}0.0906 \\
0.42\end{array}$ & $\begin{array}{c}0.1545 \\
0.27\end{array}$ \\
\hline $\begin{array}{l}\text { LDL }[\mathrm{mg} / \mathrm{dL}] \\
\mathrm{r} \\
\mathrm{p} \text {-value }\end{array}$ & $\begin{array}{c}0.0063 \\
0.956\end{array}$ & $\begin{array}{c}-0.0087 \\
0.95\end{array}$ & $\begin{array}{c}-0.0028 \\
0.98\end{array}$ & $\begin{array}{c}0.1568 \\
0.27\end{array}$ \\
\hline $\begin{array}{l}\mathrm{HDL}[\mathrm{mg} / \mathrm{dL}] \\
\mathrm{r} \\
\mathrm{p} \text {-value }\end{array}$ & $\begin{array}{c}0.0275 \\
0.8\end{array}$ & $\begin{array}{c}-0.1155 \\
0.41\end{array}$ & $\begin{array}{c}-0.0148 \\
0.89\end{array}$ & $\begin{array}{c}-0.0214 \\
0.88\end{array}$ \\
\hline $\begin{array}{l}\text { Follow up [years] } \\
r \\
\text { p-value }\end{array}$ & $\begin{array}{l}0.09 \\
0.39\end{array}$ & $\begin{array}{l}\text { NA } \\
\text { NA }\end{array}$ & $\begin{array}{c}0.122 \\
0.28\end{array}$ & $\begin{array}{l}\text { NA } \\
\text { NA }\end{array}$ \\
\hline
\end{tabular}

ALL - childhood acute lymphoblastic leukemia survivors; SBP - systolic blood pressure; DBP - diastolic blood pressure; MAP - mean arterial pressure; BMI - body mass index; SDS - standard deviation score; $r$ - Pearson correlation coefficient; ${ }^{*}$ statistically significant; NA - not applicable; LDL - low-density lipoprotein; HDL - high-density lipoprotein.

pediatric data regarding the usefulness of CIMT is still limited.

It is believed that cancer survivors, including children treated for ALL, are at particular risk of AH development. ${ }^{16,23,24}$ The main finding of the presented paper is that CIMT expressed as mean values [ $\mathrm{mm}]$ and SDS is not statistically different in childhood ALL survivors as compared to controls and between those ALL survivors with $\mathrm{AH}$ and normal BP. This is surprising since there is a lot of published data which implies a strong association between CIMT and disorders associated with atherosclerosis development. Increased CIMT was found in children with type 1 diabetes mellitus, familial hypercholesterolemia, hypertension, and metabolic syndrome..$^{2,4,7,25,26}$ Children after therapy of ALL are also at substantial risk of cardiovascular disease development in adulthood. ${ }^{15,16,27}$ It was also confirmed that cancer childhood survivors are approx. 8 times more likely to die due to cardiac-related events as compared to the general population. ${ }^{28}$

Our observations are in line with data published by Giordano et al. They demonstrated that children after ALL treatment had lower FMD of the brachial artery but not different CIMT as compared to healthy controls. ${ }^{18}$ Moreover, the study of Järvelä et al. revealed similar results since they did not find a difference in CIMT between childhood ALL survivors aged 16-30 years as compared to controls, although it needs to be stressed that one of the main aims of their study was to compare the CIMT values before and after a 16-week home-based exercise program. ${ }^{19}$

It should also be highlighted that most available pediatric studies regarding CIMT included older children and compared the mean values of CIMT in healthy subjects with a population at risk (hypertension, obesity, metabolic syndrome, and dyslipidemia). Doyon et al. established reference charts which allow a comparison CIMT-SDS in children with chronic conditions and healthy controls. ${ }^{21}$ In our study, all mean values of CIMT were computed using the LMS formula, which makes it possible to convert the measurements for specific characteristics of a child (sex, age, height).

The relationship between AH and CIMT has been confirmed in many studies. ${ }^{29,30}$ This convincing association is not in line with our results. Despite an increased number of individuals with AH in childhood ALL survivors as compared to controls, the CIMT values in these 2 populations were not statistically different.

If CIMT represents subclinical and asymptomatic atherosclerotic vascular disease which is also associated with $\mathrm{AH}$, the only explanation why CIMT is not increased in hypertensive childhood ALL survivors, as compared to controls, is that CIMT displays only morphological alterations of the vascular wall, whereas one of the earliest components of atherosclerosis is endothelial dysfunction. ${ }^{21}$ It results from the predominance of a pro-vasoconstrictory state and, if sustained and not reversed, may finally progress to morphological changes of the vascular wall including plaque formation. ${ }^{31}$

Several functional changes of the vascular wall in childhood ALL survivors may be present earlier, leading to abnormal regulation of vascular tone, and are responsible for AH development. ${ }^{32}$ Even though we found a significant positive correlation between CIMT-SDS and 24-hour SBPSDS in the ALL cohort, such a correlation was not found in controls. This may indicate some causative impact of BP on CIMT in children with ALL.

Our data cannot support a strong relationship between $\mathrm{BP}$ and CIMT in the patients studied. It is in contrast to data reported by Dawson et al., who found that SBP was independently associated with CIMT in a population of children older than 11 years. ${ }^{33}$ Kollias et al., who found 
that BP was an independent determinant of increased CIMT in healthy children aged $8-18$, made a similar observation. It is worth noting that the correlation coefficient observed in that study was low $(r=0.12)$, suggesting that CIMT is only partially predicted by BP. ${ }^{8}$

Carotid intima-media thickness is particularly influenced by a patient's age; thus, the time of first CIMT assessment may be crucial for proper adaptation of this method. ${ }^{21}$ Our study population consisted of subjects with a median age of 12 years and a median time of CIMT analysis of 5 years from ALL diagnosis. It might be too early to find structural abnormalities in the arterial wall. However, we did not find any significant correlation between CIMT and time from diagnosis of ALL, which might be explained by the relatively short time of the follow-up in the study group. The length of time that could result in morphological remodeling of the vascular wall in childhood ALL survivors still needs to be estimated. This is in line with data published by Baroncini et al., who found no significant difference in CIMT in healthy children younger than 15 years and relatively constant values of CIMT in children younger than 10 years. ${ }^{34}$ The hypothesis that our study population was examined too early also cannot be ruled out.

Dawson et al. confirmed a direct association of CIMT with total cholesterol and triglycerides in a healthy population of adolescents and young adults. ${ }^{33} \mathrm{We}$ did not find any significant correlations of CIMT ( $\mathrm{mm} / \mathrm{SDS}$ ) with total cholesterol, triglycerides, and LDL and HDL concentrations in childhood ALL survivors as well as in controls, even though the concentration of total cholesterol was higher in the ALL cohort.

This finding supports the observation of Giordano et al., who also did not confirm such a correlation although concentrations of total cholesterol, triglycerides and LDL were higher, and HDL was lower in ALL survivors as compared to controls. ${ }^{18}$ But the truth is also that we found higher HDL concentration in ALL survivors, which would have protective effect for early vascular changes in this population.

Vijayasarathi et al. showed that the only risk factor which had a negative significant correlation with CIMT was HDL concentration. In this study, total cholesterol, LDL and triglyceride concentrations were not significantly correlated with CIMT. ${ }^{25}$

Metabolic syndrome, obesity and hyperlipidemia are widely recognized causative factors of atherosclerosis in youths. Published data indicates their relation with intima-media thickening, making CIMT evaluation a useful tool for prediction of cardiovascular events in such patients. ${ }^{1,25}$ We found that z-score BMI was significantly higher in childhood ALL survivors. However, a significant correlation between z-score BMI and CIMT was found exclusively in the controls. Moreover, higher z-score BMI did not result in carotid intima-media thickening in the ALL cohort. Mean BMI as well as numbers of patients with obesity were also not different between the 2 groups. This is in line with the results of a study by Juonala et al. They found that the strength of the associations between childhood risk factors (total cholesterol, triglycerides, BP, and BMI) and CIMT is dependent on childhood age and becomes evident only in children older than 8 years. ${ }^{17}$

We are aware that our study has several limitations. The study sample was relatively small as well as the followup too short. These factors probably have had an impact upon the results. Moreover, measurements of CIMT require extreme precision, since Wiegman et al. found that CIMT increases by only $0.001 \mathrm{~mm}$ per year in healthy controls. ${ }^{35}$ Finally, since reference values of CIMT for children have not yet been set, matched-case control is required for every measurement, which is not feasible in clinical practice.

Considering the results presented in this paper as well as the abovementioned study limitations, we conclude that measurement of CIMT cannot be used as an early indicator of endothelial dysfunction in childhood ALL survivors. Based on the observations presented in this study, one may speculate that in childhood ALL survivors with $\mathrm{AH}$, the vascular wall retains its elasticity and probably responds to vasodilators. If this is so, these agents should be considered as first-line treatment of AH in young ALL survivors.

Although there are some clinical practice guidelines which provide recommendations for cardiac toxicity screening of late effects in survivors of pediatric malignancies using echocardiography, other tests are needed to predict cardiovascular risk in childhood ALL survivors at the early stage of the follow-up, in particular those with $\mathrm{AH} .{ }^{36}$ This would probably help in designing early intervention programs intended to prevent, reduce or delay cardiovascular disease in childhood and adolescence.

\section{ORCID iDs}

Tomasz Ociepa (1) https://orcid.org/0000-0002-0068-4436 Wioletta Posio (1) https://orcid.org/0000-0001-7437-2614 Marcin Sawicki (1) https://orcid.org/0000-0003-0129-2343 Tomasz Urasiński (1) https://orcid.org/0000-0003-3107-8575

\section{References}

1. Urbina EM, Williams RV, Alpert BS, et al. American Heart Association Atherosclerosis, Hypertension, and Obesity in Youth Committee of the Council on Cardiovascular Disease in the Young. Noninvasive assessment of subclinical atherosclerosis in children and adolescents: Recommendations for standard assessment for clinical research. A scientific statement from the American Heart Association. Hypertension. 2009;54(5):919-950.

2. Civilibal M, Duru NS, Elevli M. Subclinical atherosclerosis and ambulatory blood pressure in children with metabolic syndrome. Pediatr Nephrol. 2014;29(11):2197-2204.

3. Rodrigues TM, Barra CB, Santos JL, Goulart EM, Ferreira AV, Silva IN. Cardiovascular risk factors and increased carotid intima-media thickness in young patients with congenital adrenal hyperplasia due to 21-hydroxylase deficiency. Arch Endocrinol Metab. 2015;59(5): 541-547.

4. Rostampour N, Fekri K, Hashemi-Dehkordi E, Obodiat M. Association between vascular endothelial markers and carotid intima-media thickness in children and adolescents with type 1 diabetes mellitus. J Clin Diagn Res. 2017;11(9):SC01-SC05. 
5. Krawczuk-Rybak M, Tomczuk-Ostapczuk M, Panasiuk A, Goscik E. Carotid intima-media thickness in young survivors of childhood cancer. J Med Imaging Radiat Oncol. 2017;61(1):85-92.

6. Vatanen A, Sarkola T, Ojala TH, et al. Radiotherapy-related arterial intima thickening and plaque formation in childhood cancer survivors detected with very-high resolution ultrasound during young adulthood. Pediatr Blood Cancer. 2015;62(11):2000-2006.

7. Bonafini S, Giontella A, Tagetti A, et al. Markers of subclinical vascular damages associate with indices of adiposity and blood pressure in obese children. Hypertens Res. 2019;42(3):400-410. doi:10.1038/ s41440-018-0173-7

8. Kollias A, Psilopatis I, Karagiaouri E, et al. Adiposity, blood pressure, and carotid intima-media thickness in Greek adolescents. Obesity (Silver Spring). 2013;21(5):1013-1017.

9. Lipshultz SE, Adams MJ, Colan SD, et al; American Heart Association Congenital Heart Defects Committee of the Council on Cardiovascular Disease in the Young; Council on Basic Cardiovascular Sciences; Council on Cardiovascular and Stroke Nursing; Council on Cardiovascular Radiology. Long-term cardiovascular toxicity in children, adolescents, and young adults who receive cancer therapy: Pathophysiology, course, monitoring, management, prevention, and research directions. A scientific statement from the American Heart Association. Circulation. 2013;128(17):1927-1995.

10. Oeffinger KC. Are survivors of acute lymphoblastic leukemia (ALL) at increased risk of cardiovascular disease? Pediatr Blood Cancer. 2008; 50(2 Suppl):462-467.

11. Kubota M, Nakata R, Adachi S, et al. Plasma homocysteine, methionine and S-adenosylhomocysteine levels following high-dose methotrexate treatment in pediatric patients with acute lymphoblastic leukemia or Burkitt lymphoma: Association with hepatotoxicity. Leuk Lymphoma. 2014;55(7):1591-1595.

12. Sandoo A, van Zanten JJ, Metsios GS, Carroll D, Kitas GD. The endothelium and its role in regulating vascular tone. Open Cardiovasc Med J. 2010;4:302-312.

13. Vora A, Goulden N, Wade R, et al. Treatment reduction for children and young adults with low-risk acute lymphoblastic leukaemia defined by minimal residual disease (UKALL 2003): A randomised controlled trial. Lancet Oncol. 2013;14(3):199-209.

14. Pui CH, Pei D, Campana D, et al. A revised definition for cure of childhood acute lymphoblastic leukemia. Leukemia. 2014;28(12):23362343. doi:10.1038/leu.2014.142

15. Levy E, Samoilenko M, Morel S, et al. Cardiometabolic risk factors in childhood, adolescent and young adult survivors of acute lymphoblastic leukemia: A Petale Cohort. Sci Rep. 2017;7:17684. doi:10.1038/ s41598-017-17716-0

16. Nottage KA, Ness KK, Li C, Srivastava D, Robison LL, Hudson MM. Metabolic syndrome and cardiovascular risk among long-term survivors of acute lymphoblastic leukaemia: From the St. Jude Lifetime Cohort. Br J Haematol. 2014;165(3):364-374.

17. Juonala M, Magnussen CG, Venn A, et al. Influence of age on associations between childhood risk factors and carotid intima-media thickness in adulthood: The Cardiovascular Risk in Young Finns Study, the Childhood Determinants of Adult Health Study, the Bogalusa Heart Study, and the Muscatine Study for the International Childhood Cardiovascular Cohort (i3C) Consortium. Circulation. 2010;122(24): 2514-2520.

18. Giordano P, Muggeo P, Delvecchio M, et al. Endothelial dysfunction and cardiovascular risk factors in childhood acute lymphoblastic leukemia survivors. Int J Cardiol. 2017;228:621-627.

19. Järvelä LS, Niinikoski H, Heinonen OJ, Lähteenmäki PM, Arola M, Kemppainen J. Endothelial function in long-term survivors of childhood acute lymphoblastic leukemia: Effects of a home-based exercise program. Pediatr Blood Cancer. 2013;60(9):1546-1551.
20. Touboul PJ, Hennerici MG, Meairs S, et al. Mannheim carotid intimamedia thickness and plaque consensus (2004-2006-2011). An update on behalf of the advisory board of the $3^{\text {rd }}, 4^{\text {th }}$ and $5^{\text {th }}$ watching the risk symposia, at the $13^{\text {th }}, 15^{\text {th }}$ and $20^{\text {th }}$ European Stroke Conferences, Mannheim, Germany, 2004, Brussels, Belgium, 2006, and Hamburg, Germany, 2011. Cerebrovasc Dis. 2012;34(4):290-296.

21. Doyon A, Kracht D, Bayazit AK, et al. Carotid artery intima-media thickness and distensibility in children and adolescents: Reference values and role of body dimensions. Hypertension. 2013;62(3):550-556.

22. Wühl E, Witte K, Soergel M, Mehls O, Schaefer F; German Working Group on Pediatric Hypertension. Distribution of 24-h ambulatory blood pressure in children: Normalized reference values and role of body dimensions. J Hypertens. 2002;20(10):1995-2007.

23. Ociepa T, Bartnik M, Zielezińska K, Urasiński T. Prevalence and risk factors for arterial hypertension development in childhood acute lymphoblastic leukemia survivors. J Pediatr Hematol Oncol. 2019;41(3): 175-180.

24. Veringa SJ, van Dulmen-den Broeder E, Kaspers GJ, Veening MA. Blood pressure and body composition in long-term survivors of childhood acute lymphoblastic leukemia. Pediatr Blood Cancer. 2012; 58(2):278-282.

25. Vijayasarathi A, Goldberg SJ. Comparison of carotid intima-media thickness in pediatric patients with metabolic syndrome, heterozygous familial hyperlipidemia and normals. J Lipids. 2014;2014:546863. doi:10.1155/2014/546863

26. Lande MB, Carson NL, Roy J, Meagher CC. Effects of childhood primary hypertension on carotid intima media thickness: A matched controlled study. Hypertension. 2006;48(1):40-44.

27. Saultier $P$, Auquier $P$, Bertrand $Y$, et al. Metabolic syndrome in longterm survivors of childhood acute leukemia treated without hematopoietic stem cell transplantation: An L.E.A. study. Haematologica. 2016;101(12):1603-1610.

28. Mertens AC, Yasui Y, Neglia JP, et al. Late mortality experience in fiveyear survivors of childhood and adolescent cancer: The Childhood Cancer Survivor Study. J Clin Oncol. 2001;19(13):3163-3172.

29. Tomiyama H, Ishizu T, Kohro T, et al. Longitudinal association among endothelial function, arterial stiffness and subclinical organ damage in hypertension. Int J Cardiol. 2018;253:161-166.

30. Urbina EM. Abnormalities of vascular structure and function in pediatric hypertension. Pediatr Nephrol. 2016;31(7):1061-1070.

31. Chhabra N. Endothelial dysfunction: A predictor of atherosclerosis. Internet J Med Update. 2009;4(1):33-41.

32. Ociepa T, Bartnik M, Zielezinska K, Prokowska M, Urasinska E, Urasinski T. Abnormal correlation of circulating endothelial progenitor cells and endothelin-1 concentration may contribute to the development of arterial hypertension in childhood acute lymphoblastic leukemia survivors. Hypertens Res. 2016;39(7):530-535.

33. Dawson JD, Sonka M, Blecha MB, Lin W, Davis PH. Risk factors associated with aortic and carotid intima-media thickness in adolescents and young adults: The Muscatine Offspring Study. J Am Coll Cardiol. 2009;53(24):2273-2279.

34. Baroncini LA, Sylvestre Lde C, Pecoits Filho R. Assessment of intimamedia thickness in healthy children aged 1 to 15 years. Arq Bras Cardiol. 2016;106(4):327-332.

35. Wiegman A, de Groot E, Hutten BA, et al. Arterial intima-media thickness in children heterozygous for familial hypercholesterolaemia. Lancet. 2004;363(9406):369-370.

36. Children's Oncology Group. Long-term Follow-up Guidelines for Survivors of Childhood, Adolescent and Yound Adult Cancer. Version 5.0 - October 2018. http://www.survivorshipguidelines.org/ pdf/2018/COG_LTFU_Guidelines_v5.pdf. Monrovia, CA: Children's Oncology Group; 2018. 